\title{
Transcatheter or surgical repair for degenerative mitral regurgitation in elderly patients: A propensity-weighted analysis
}

Nicola Buzzatti, MD, ${ }^{a}$ Mathias Van Hemelrijck, MD, ${ }^{\mathrm{b}}$ Paolo Denti, MD, ${ }^{\mathrm{a}}$ Stefania Ruggeri, MS, ${ }^{\mathrm{a}}$ Davide Schiavi, BS, ${ }^{\mathrm{a}}$ Iside Stella Scarfò, MD ${ }^{\mathrm{a}}$ Diana Reser, MD ${ }^{\mathrm{b}}$ Maurizio Taramasso, MD, Alberto Weber, MD, ${ }^{\mathrm{b}}$ Giovanni La Canna, MD, ${ }^{\mathrm{a}}$ Michele De Bonis, MD, ${ }^{\mathrm{a}}$ Francesco Maisano, MD, ${ }^{\mathrm{b}}$ and Ottavio Alfieri, $\mathrm{MD}^{\mathrm{a}}$

\section{ABSTRACT}

Objective: To compare the outcomes of MitraClip and surgical mitral repair in low-intermediate risk elderly patients affected by degenerative mitral regurgitation (DMR).

Methods: We retrospectively selected patients aged $\geq 75$ years, with Society of Thoracic Surgeons Predicted Risk Of Mortality (STS-PROM) $<8 \%$, submitted to MitraClip $(n=100)$ or isolated surgical repair $(n=206)$ for DMR at 2 centers between January 2005 and May 2017. To adjust for baseline imbalances, we used a propensity score model for average treatment effect on survival.

Results: After weighting, MitraClip showed fewer postoperative complications $(P<.05)$ but increased residual mitral regurgitation $(\mathrm{MR}) \geq 2(27.0 \%$ vs $2.8 \%$, $P<.001)$ compared with surgery. One-year survival was greater after MitraClip compared with surgery $(97.6 \%$ vs $95.3 \%$, hazard ratio [HR], 0.09 ; confidence interval $[\mathrm{CI}], 0.02-0.37, P=.001)$, whereas 5 -year survival was lower $(34.5 \%$ vs $82.2 \%$ respectively, HR, 4.12; CI, 2.31-7.34, $P<.001)$. Greater STS-PROM (HR, 1.18; CI, 1.12-1.24, $P<.001)$ and MR $\geq 3+$ recurrence (HR, 2.18; CI, 1.07-4.48, $P=.033$ ) were associated with reduced survival. 5-year MR $\geq 3+$ was more frequent after MitraClip compared with surgery: $36.9 \%$ versus $3.9 \%$, odds ratio, 11.4; CI, 4.40-29.68, $P<.001$.

Conclusions: In elderly patients affected by DMR and STS-PROM $<8 \%$, the average effect of MitraClip resulted in lower acute postoperative complications and improved 1-year survival compared with surgery. However, MitraClip was associated with greater MR recurrence and reduced survival beyond 1 year. Long-term survival was impaired by patients' greater risk profile and MR recurrence. Early results are promising, but in the setting of operable patients with life expectancy beyond 1 year, the quality bar for transcatheter mitral repair needs to be raised. (J Thorac Cardiovasc Surg 2019;158:86-94)

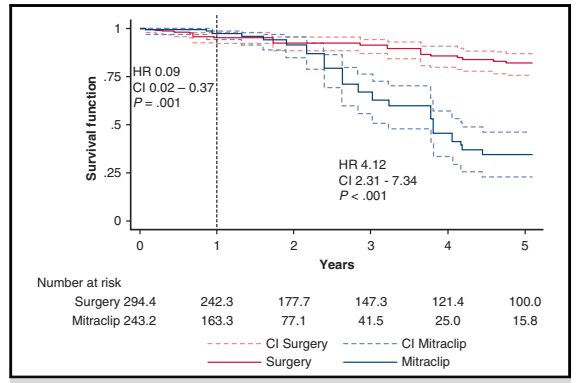

ATE-weighted Kaplan-Meier survival estimates after MitraClip or surgical repair for DMR.

\section{Central Message}

In low-intermediate risk elderly patients with DMR, MitraClip was associated with survival improvement within but impairment beyond 1-year compared with surgery. Greater risk and MR recurrence reduced survival.

\section{Perspective}

Whether MitraClip should be performed in low-intermediate risk patients is debated. Improvement in early mortality compared with surgery is promising, but the impairment of long-term survival with high MR recurrence warrants improved efficacy, through refined patient selection and procedure execution. In the setting of operable patients, the quality bar for transcatheter mitral repair needs to be raised.

See Commentaries on pages 95 and 97.
From the ${ }^{\mathrm{a} C a r d i a c}$ Surgery Department, San Raffaele Scientific Institute, Milan, Italy; and ${ }^{\mathrm{b}}$ Cardiac Surgery Department, Zurich University Hospital, Zurich, Switzerland.

Drs Buzzatti and Van Hemelrijck contributed equally to this article.

Received for publication Dec 16, 2016; revisions received Dec 3, 2018; accepted for publication Jan 8, 2019; available ahead of print Feb 20, 2019.

Address for reprints: Nicola Buzzatti, MD, Cardiac Surgery Department, via Olgettina 60, 20132 Milan, Italy (E-mail: buzzatti.nicola@hsr.it).

$0022-5223 / \$ 36.00$

Copyright (c) 2019 by The American Association for Thoracic Surgery

https://doi.org/10.1016/j.jtcvs.2019.01.023
The elderly patient represents an ever-growing subset of patients affected by degenerative mitral regurgitation (DMR). In these patients, the best balance between the acute risk of

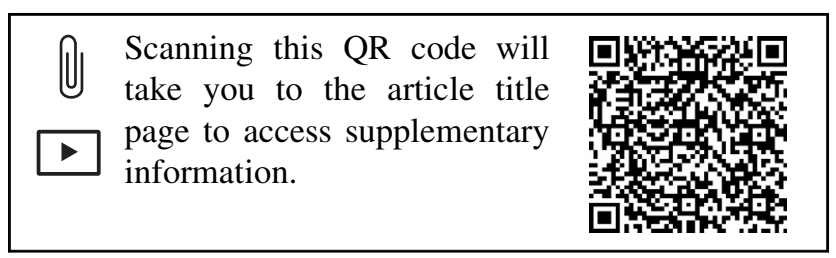




$$
\begin{aligned}
& \text { Abbreviations and Acronyms } \\
& \begin{aligned}
\text { ASMD }= & \text { absolute standardized mean } \\
& \text { differences }
\end{aligned} \\
& \text { ATE }=\text { average treatment effect } \\
& \mathrm{CI}=\text { confidence interval } \\
& \text { DMR }=\text { degenerative mitral regurgitation } \\
& \text { GEE = generalized estimating equation } \\
& \text { HR = hazard ratio } \\
& \text { IPTW = inverse probability of treatment } \\
& \text { weight } \\
& \text { MR = mitral regurgitation } \\
& \text { OR } \quad=\text { odds ratio } \\
& \text { STS-PROM }=\text { Society of Thoracic Surgeons } \\
& \text { Predicted Risk Of Mortality }
\end{aligned}
$$

the operation and the long-term benefit is particularly difficult to ascertain. Indeed, compared with younger patients, they suffer per se a heavier burden after surgery ${ }^{1-3}$ while having a naturally reduced life expectancy and concomitant comorbidities that can frustrate the benefit of the operation.

Despite the good results provided by mitral surgery for DMR, even in the setting of selected elderly patients, ${ }^{2,4}$ until 10 years ago up to $50 \%$ of all patients affected by severe mitral regurgitation (MR) were not submitted to treatment because of a perceived excessively high procedural risk, one of the main reasons being advanced age. $^{5}$

In this setting, transcatheter mitral repair with the MitraClip System (Abbott Vascular, Santa Clara, Calif) provided over the last decade excellent results in terms of safety, despite the high-risk profile of the treated patients, at the price of a suboptimal MR reduction. ${ }^{6-8}$ Today, MitraClip is recognized as a viable option to treat high-risk or inoperable symptomatic patients after Heart Team discussion. ${ }^{9,10}$

In the daily practice, however, many elderly patients do not actually show specific high-risk features but rather fall into the "low-to-intermediate" risk category. Whether the access to MitraClip should be opened to these "gray" patients, with MitraClip being preferred to surgery as the first-line option, is already debated but not yet supported by any specific data.

The Endovascular Valve Edge-to-Edge Repair Study (EVEREST) II randomized patients between MitraClip and surgery but, as per study design, information on the real-world elderly DMR population is difficult to infer, because of the study cohort's young age, mixed etiologies, and strict inclusion/exclusion criteria. ${ }^{11}$ Subsequently, the High and Intermediate Risk Degenerative Mitral Regurgitation Treatment (HiRiDe) trial was specifically designed to randomize elderly patients affected by DMR but was prematurely terminated due to severe enrolling difficulties. Up until now therefore, only few retrospective unbalanced data were available on this topic. ${ }^{7}$

Given this lack of knowledge, we sought to compare the outcomes following MitraClip or surgical mitral repair in the typical, real-world, low-to-intermediate risk elderly population currently referred to mitral repair for DMR at 2 European leading mitral centers.

\section{METHODS}

We retrospectively selected all consecutive elderly patients submitted to MitraClip or surgical mitral repair at 2 mitral centers between January 2005 and May 2017: San Raffaele Scientific Institute (Milan, Italy) and Zurich University Hospital (Zurich, Switzerland). Timeframe was on purpose selected to include also patients treated surgically before MitraClip's introduction in clinical practice to have more similar patients in the surgical arm: patients with a greater-risk profile who would get shifted to percutaneous treatment after it became available.

\section{Study Design}

Figure 1 describes the flowchart for patients' inclusion into the study. Patients submitted to mitral repair aged $\geq 75$ years at the time of operation and affected by severe MR due to leaflet prolapse with or without flail (DMR) were included into the study.

Patients with MR etiologies other than DMR were excluded. Patients who underwent immediate mitral replacement as intention-to-treat were excluded, as well as patients who received associated procedures as tricuspid valve, arrhythmia ablation, coronary artery bypass grafting, aortic valve, ascending aorta, and myectomy procedures. Ten patients receiving concomitant left atrial appendage closure were included, 4 in the MitraClip and 6 in the surgical group. Patients with associated preoperative tricuspid regurgitation $\geq 3+$ were excluded.

All patients treated with MitraClip underwent a comprehensive Heart Team discussion, which included the surgical risk assessment using the Society of Thoracic Surgeons Predicted Risk Of Mortality (STS-PROM). To focus on low and intermediate risk, patients with preoperative STS-PROM $\geq 8 \%$ were excluded.

Although EVEREST II eligibility criteria for MitraClip were used as a reference, ${ }^{12}$ a number of patients outside these was also treated. Patients with target leaflet calcifications and leaflet perforations were excluded.

The study complied with the Declaration of Helsinki and it was approved by the institutions' ethics committees.

\section{Data Collection}

All patients underwent a preoperative transthoracic and transoesophageal ecocardiographic mitral examination. Patients in the MitraClip group underwent an in-hospital prospective data collection pathway. Data of surgical patients were retrospectively retrieved from Institutional databases.

After the operation, patients in the MitraClip group were enrolled in a dedicated echocardiographic outpatient clinic, undergoing a transthoracic echocardiogram at every visit $(1,6$, and 12 months and every year thereafter). Surgical patients and patients missing follow-up visits were contacted via a telephone call and asked to provide their follow-up echocardiograms.

MR was graded according to European Association of Echocardiography and Mitral Valve Academic Research Consortium recommendations as: $1+$ (mild), $2+$ (mild-to-moderate), $3+$ (moderate-to-severe), and 4+ (severe). ${ }^{13,14}$ Because of the potential inaccuracy of conventional parameters for MR quantification in the setting of double-orifice mitral valve, the jet-related parameters (vena contracta, effective regurgitant orifice) were used only in presence of a single-orifice regurgitant jet, 


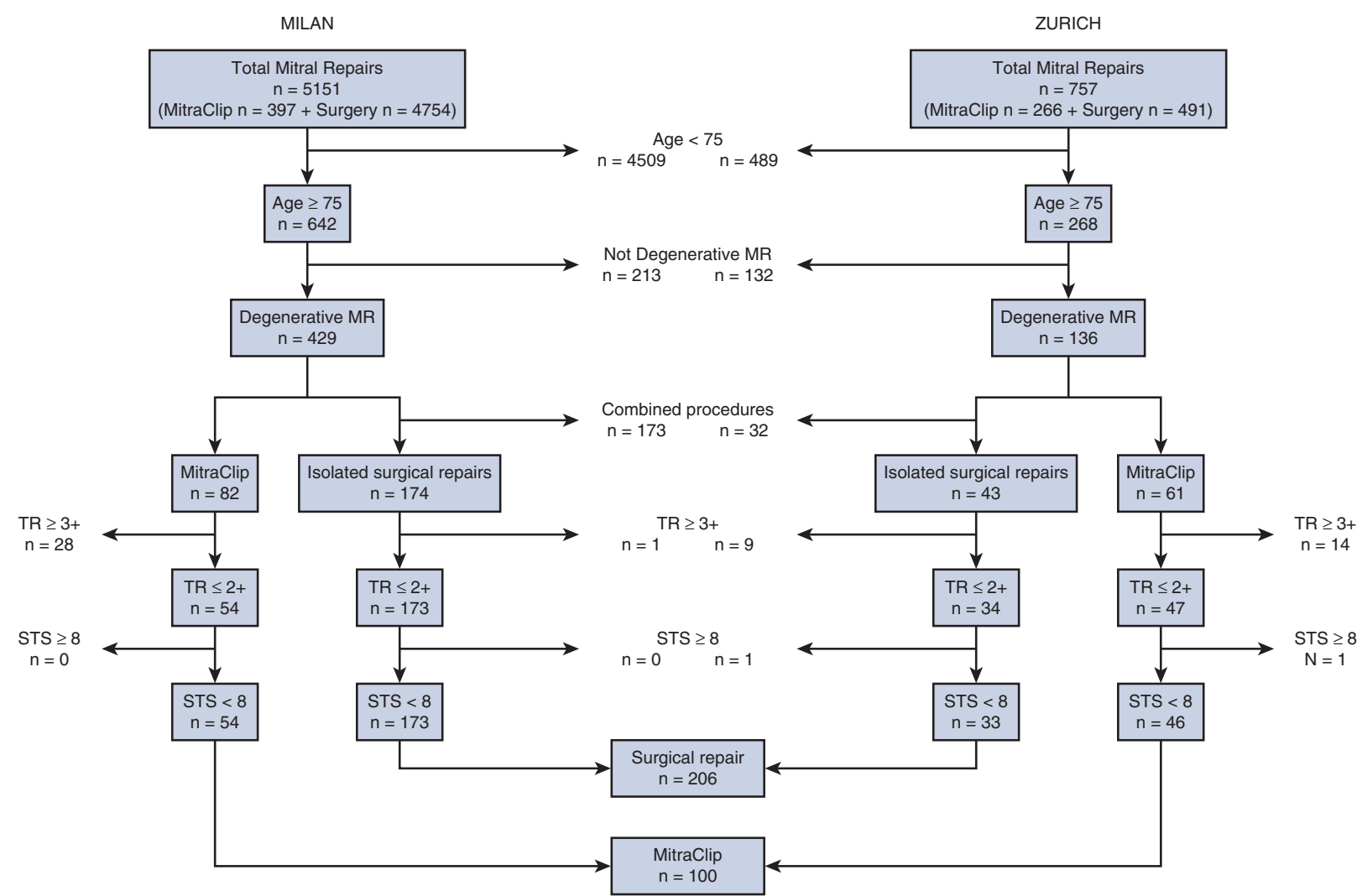

FIGURE 1. Flowchart of study patients' selection. $M R$, Mitral regurgitation; TR, tricuspid regurgitation; STS, Society of Thoracic Surgeons.

whereas the regurgitant fraction was used in multiple-jet MR. ${ }^{15}$ Residual MR was captured at the end of the procedure in the operating room.

Among surgical patients, all patients treated at San Raffaele Scientific Institute $(\mathrm{n}=173,84.0 \%)$ underwent mid-sternotomy, whereas all patients treated at Zurich University Hospital $(\mathrm{n}=33,16.0 \%)$ underwent a minithoracotomy approach.

\section{Outcomes}

The main endpoints of the study were the comparisons of survival and MR recurrence between MitraClip and surgical patients.

\section{Statistical Analyses}

To adjust for imbalance in baseline characteristics between MitraClip and surgical patients, a propensity score to weight the sample with inverse probability of treatment weight (IPTW) was used so that the distribution of measured baseline covariates was independent of treatment assignment. ${ }^{16}$

Propensity scores were estimated running multiple logistic models including various combinations of preoperative variables. The best balance was achieved with the following 10 variables: age at operation, sex, body mass index categorized as normal (20-30) or not normal $(<20$ or $>30)$, serum creatinine, atrial fibrillation, New York Heart Association class $\geq \mathrm{III}$, ejection fraction, systolic pulmonary artery pressure, isolate P2 prolapse, and STS-PROM.

Weights were designed to estimate the average treatment effect (ATE): the average effect of moving an entire population from surgery to MitraClip. ATE weights were chosen by the odds to estimate the average effect of MitraClip in a pseudo-sample of patient with a covariate distribution similar to that of the overall sample, thus simulating a randomized trial.
Weights were trimmed at 95th percentile to ameliorate efficiency and reduce the influence of outlying observations. ${ }^{17}$ Balance of confounders between groups was assessed calculating absolute standardized mean differences (ASMD) for the original and weighted sample according to Austin and Stuart. ${ }^{18}$ Balance was considered optimal for ASMD $<0.10$ and sufficient for ASMD $<0.20$, according to previous literature. ${ }^{19,20}$

\section{Endpoint Analysis}

Analyses were conducted using Stata software version 13 (StataCorp LLC, College Station, Tex) and SAS 9.3 (SAS Institute, Cary, NC). Unweighted and weighted means were calculated and differences between groups were compared by nonparametric test based on Somers' D statistic using the somersd package. Numbers in brackets report interquartile range. Crude and weighted rates of endpoints were calculated and compared using the Kaplan-Meier estimates.

A Cox model weighted on IPTW was used to estimate the hazard ratio (HR) of death between MitraClip and surgical patients, allowing for changes in the proportionality of hazards over time. The proportional hazard assumption for Cox models was assessed using Schoenfeld residuals and global test. To choose variables included into the final Cox model, we tested extensively several variables and selected the most clinically interesting, with a $P$ value $<.05$ at univariable analysis. The proportional hazard assumption was also evaluated for each variable. The final variables included into the survival model were "Treatment" (MitraClip vs surgery, not proportional, therefore inserted as a time-dependent covariate), "STSPROM" (proportional over time), and "follow-up MR" (as a binary MR $\geq 3+$ time-varying covariate, splitting the covariate and setting a time of entry and a time of exit from each status). Robust variance estimator was 
used to account for the estimation of weights. "Institution" (Milan/Zurich) was inserted into the Cox model for survival as a cluster variable.

To describe the time course of MR, we performed a longitudinal analysis using generalized estimating equations (GEEs) with random intercept for repeated data. The GEE method was applied because of the possible intrapatient correlations. This method allowed to perform a weighted analysis with a binary model for a repeated measure. Longitudinal analysis with GEE model to assess predictors of MR $\geq 3+$ recurrence in the subgroup of MitraClip patients who had MR $\leq 2+$ at the end of the procedure was also conducted. Variables included into this model were institution, valve calcifications, isolated P2 prolapse, and residual $2+$ MR. These covariates were chosen based on their clinical importance in the development of MR, their number of events, and the total number of patients/events. Because of the limited number of cases, this subanalysis was limited to within the first 3 years after the procedure. $P$ values $<.05$ were considered significant.

\section{RESULTS}

The final number of patients included into the study was 306, among whom 100 (32.7\%) had undergone MitraClip and $206(67.3 \%)$ were submitted to surgical repair. The number of patients per each Institution was as follows: at San Raffaele Scientific Institute, $\mathrm{n}=227,54$ (23.8\%)
MitraClip procedures; at Zurich University Hospital $\mathrm{n}=79,46(58.2 \%)$ MitraClip procedures.

Major baseline patient characteristics before and after propensity-score weighting are summarized in Table 1. At baseline, patients in the MitraClip group were older, at greater risk, and affected by more comorbidities compared with surgical patients, but propensity weighting allowed adequate balance of the 2 groups.

Intraoperative details are reported in Table 2. Postoperatively, 4 deaths were observed: 2 patients in the MitraClip group (1 multiorgan failure after emergent conversion to surgery, 1 electromechanical dissociation) and 2 surgical patients ( 1 hemorrhagic shock due to heart rupture, 1 multiorgan failure). At weighted analysis, the risk of all postoperative complications was significantly reduced after MitraClip compared with surgery (Table 3). In contrast, greater degrees of residual MR were observed after MitraClip (Table 3, Figure E1).

Seven $(2.3 \%)$ patients were missing at follow-up. Median follow-up time was 1.38 [0.67-2.85] years in MitraClip and $3.2[1.28-6.33]$ years in surgery.

TABLE 1. Preoperative patients' characteristics

\begin{tabular}{|c|c|c|c|c|c|c|c|}
\hline & \multicolumn{4}{|c|}{ Unweighted } & \multicolumn{3}{|c|}{ Weighted } \\
\hline & $\begin{array}{l}\text { Surgery } \\
(n=206)\end{array}$ & $\begin{array}{c}\text { MitraClip } \\
(n=100)\end{array}$ & $P$ value & $\operatorname{ASMD}(\%)$ & $\begin{array}{c}\text { Surgery } \\
(\text { SoW }=\mathbf{3 0 5 . 0 8})\end{array}$ & $\begin{array}{c}\text { MitraClip } \\
(\text { SoW }=\mathbf{2 4 7 . 4 9 )}\end{array}$ & $\operatorname{ASMD}(\%)$ \\
\hline \multicolumn{8}{|l|}{ Clinical } \\
\hline Age, y & $78.8 \pm 3.13$ & $82.9 \pm 3.5$ & $<.001$ & 124 & $80.1 \pm 6.89$ & $81.2 \pm 6.27$ & 15 \\
\hline Male sex & $118(57)$ & $55(55)$ & .706 & 5 & $175.3(57)$ & $141.0(57)$ & 1 \\
\hline \multicolumn{8}{|l|}{ BMI } \\
\hline$<20$ or $>30$ & $25(12)$ & $20(20)$ & & & $47.5(16)$ & 43.7 (17) & \\
\hline $20-30$ & $181(88)$ & $80(80)$ & .305 & 22 & $257.6(84)$ & $203.8(83)$ & 3 \\
\hline Creatinine, $\mathrm{mg} / \mathrm{dL}$ & $0.99[0.81 ; 1.19]$ & $1.08[0.89 ; 1.34]$ & .018 & 27 & $1[0.82 ; 1.2]$ & $1.01[0.86 ; 1.28]$ & 2 \\
\hline CAD & $41(20)$ & $28(28)$ & .112 & 19 & $62.6(20)$ & $73.2(29)$ & 12 \\
\hline COPD & $14(6.8)$ & $19(19)$ & .001 & 37 & $30.7(10)$ & 47.1 (19) & 14 \\
\hline CVD & $8(3.9)$ & $9(9)$ & .067 & 21 & $11.4(4)$ & $25.0(10)$ & 14 \\
\hline PVD & $14(6.8)$ & $13(13)$ & .073 & 21 & $19(6)$ & $38.2(15)$ & 16 \\
\hline Atrial fibrillation & $25(12)$ & $33(33)$ & $<.001$ & 52 & $86.8(28)$ & $83.1(34)$ & 6 \\
\hline Previous cardiac surgery & $2(1.0)$ & $9(9)$ & $<.001$ & 37 & $2.2(1)$ & $31.6(12)$ & 20 \\
\hline NYHA class III-IV & $81(39)$ & $66(66)$ & $<.001$ & 55 & $143.7(47)$ & $133.7(54)$ & 8 \\
\hline \multicolumn{8}{|l|}{ Echocardiographic } \\
\hline $\mathrm{EDD}, \mathrm{mm}$ & $54.6 \pm 6.18$ & $55.3 \pm 7.05$ & .409 & 10 & $55.0 \pm 9.71$ & $54.8 \pm 13.13$ & 2 \\
\hline $\mathrm{ESD}, \mathrm{mm}$ & $32.7 \pm 6.55$ & $33.9 \pm 8.59$ & .203 & 17 & $25.9 \pm 21.17$ & $26.1 \pm 29.09$ & 1 \\
\hline $\mathrm{EF}, \%$ & $60[58 ; 66]$ & $60[55 ; 66.5]$ & .185 & 19 & $60[58 ; 65]$ & $60[58 ; 68]$ & 2 \\
\hline sPAP, mm Hg & $37[30 ; 45]$ & $45[30.5 ; 54.5]$ & .007 & 34 & $40[30 ; 47]$ & $42[30 ; 54]$ & 4 \\
\hline $\begin{array}{l}\text { Isolated posterior leaflet } \\
\text { prolapse }\end{array}$ & $164(80)$ & $67(67)$ & .016 & 29 & $233.5(77)$ & $175.3(71)$ & 7 \\
\hline Isolate $\mathrm{P} 2$ prolapse & $136(66)$ & $53(53)$ & .028 & 29 & $193.3(63)$ & $150.2(61)$ & 3 \\
\hline \multicolumn{8}{|l|}{ STS scores } \\
\hline PROM, \% & $1.64[1.30 ; 2.41]$ & $2.99[2.29 ; 4.38]$ & $<.001$ & 103 & $1.91[1.43 ; 3.24]$ & $2.48[1.91 ; 3.49]$ & 12 \\
\hline MM, \% & $14.88[12.32 ; 18.06]$ & $19.21[15.47 ; 22.9]$ & $<.001$ & 75 & $16.2[13 ; 21.2]$ & $17.3[14.6 ; 21.1]$ & 8 \\
\hline
\end{tabular}

Numbers in brackets report interquartile range. $A S M D$, Absolute standardized mean difference; SoW, sum of weights; $B M I$, body mass index; $C A D$, coronary artery disease; $C O P D$, chronic obstructive pulmonary disease; $C V D$, cerebrovascular disease; $P V D$, peripheral vascular disease; $N Y H A$, New York Heart Association; $E D D$, end-diastolic diameter; $E S D$, end-systolic diameter; $E F$, ejection fraction; $S P A P$, systolic pulmonary artery pressure; STS, Society of Thoracic Surgeons; PROM, Predicted Risk Of Mortality; $M M$, morbidity and mortality. 
TABLE 2. Intraoperative data

\begin{tabular}{|c|c|c|}
\hline & $\begin{array}{c}\text { Surgery } \\
\text { SoW }=\mathbf{3 0 5 . 0 8}\end{array}$ & $\begin{array}{c}\text { MitraClip } \\
\text { SoW }=247.49\end{array}$ \\
\hline Total clip time, min & & $89.3 \pm 46.82$ \\
\hline CPB time, $\min$ & $88.5 \pm 37.12$ & \\
\hline Crossclamp time, min & $63.2 \pm 26.11$ & \\
\hline \multicolumn{3}{|l|}{ Number of clips, $\mathrm{n}(\%)$} \\
\hline 1 & & $34.9(14)$ \\
\hline 2 & & 119.1 (48) \\
\hline 3 & & $51.1(21)$ \\
\hline Associated LAA closure & $6.7(2.6)$ & $9.9(4.8)$ \\
\hline \multicolumn{3}{|l|}{ Surgical access, n (\%) } \\
\hline Sternotomy & $138.4(45)$ & \\
\hline Minithoracotomy & $166.7(55)$ & \\
\hline \multicolumn{3}{|l|}{ Surgical techniques, $\mathrm{n}(\%)$} \\
\hline Resection & $150.0(49)$ & \\
\hline Neochordae & $70.9(23)$ & \\
\hline Edge to edge & $105.2(34)$ & \\
\hline Cleft closure & $42.3(14)$ & \\
\hline Ring implantation, n (\%) & $297.2(97)$ & \\
\hline Mean ring size & $32.7 \pm 3.37$ & \\
\hline II Pump run, n (\%) & $21.3(7)$ & \\
\hline Conversion to replacement, $\mathrm{n}(\%)$ & $9.7(3.2)$ & $17.1(6.9)$ \\
\hline
\end{tabular}

After IPTW, 1-year survival was 97.6\% (95\% confidence interval [CI], 94.0-99.0) in MitraClip versus 95.3\% (95\% CI, 92.1-97.2) in surgery, whereas 5-year survival was $34.5 \%(95 \% \mathrm{CI}, 22.9-46.4)$ versus $82.2 \%(95 \% \mathrm{CI}$, 75.5-87.2) respectively (Figure 2). The hazard of mortality for patients in the MitraClip group was lower in the first year (HR, 0.09; 95\% CI, 0.02-0.37, $P=.001$ ) but significantly greater during the following years (HR, 4.12; 95\% CI, 2.31-7.34, $P<.001$ ). When included into the same Cox extended model both preoperative STS-PROM (HR, $1.18 ; 95 \% \mathrm{CI}, 1.12-1.24, P<.001)$ and recurrence of MR $\geq 3+(\mathrm{HR}, 2.19 ; 95 \% \mathrm{CI}, 1.07-4.48, P=.033$ ) also predicted increased hazard of mortality (Table 4 ).

The raw number of echocardiograms available along follow-up is reported in Table E1. ATE-weighted longitudinal mixed model with GEE for MR is depicted in Figure 3. Worse MR degrees were significantly more frequent in MitraClip compared with surgical patients: 5-year estimate for MR $\geq 3+$ was $36.9 \%$ after MitraClip versus $3.9 \%$ after surgery (odds ratio [OR], 11.4; 95\% CI, 4.40-29.68, $P<.001$ ).

In the MitraClip group, acute residual 2+ MR was associated with worse follow-up MR (OR, 12.0; 95\% CI, 3.2244.6, $P<.001)$. A difference in follow-up MR was also observed between centers (OR, 0.10; 95\% CI, 0.02-0.48, $P=.004)$, Table 5 .

A total of 10 (6 MitraClip and 4 surgical) patients required a new mitral intervention/operation. Median time
TABLE 3. Postoperative outcomes

\begin{tabular}{lccr}
\hline & $\begin{array}{c}\text { Surgery } \\
\text { SoW }=\mathbf{3 0 5 . 0 8}\end{array}$ & $\begin{array}{c}\text { MitraClip } \\
\text { SoW }=\mathbf{2 4 7 . 4 9}\end{array}$ & $\boldsymbol{P}$ value \\
\hline Residual MR $\geq 2+$ & $8.5(2.8)$ & $67.7(27)$ & $<.001$ \\
\hline LCOS & $52.8(17)$ & $8.0(3.3)$ & .001 \\
\hline Inotropes $>$ MD & $124.7(41)$ & $18.0(7.3)$ & $<.001$ \\
\hline AKI & $134.2(45)$ & $26.3(11)$ & $<.001$ \\
\hline Ventilation hours & $15[11 ; 19]$ & $5[0 ; 10]$ & $<.001$ \\
\hline Ventilation $>24$ h & $37.2(12)$ & $1.1(0.5)$ & $<.001$ \\
\hline NIMV & $61.9(24)$ & $9.8(6.2)$ & .002 \\
\hline Sepsis & $11.3(3.7)$ & $1.2(0.5)$ & .118 \\
\hline Serious bleeding & $26.1(15)$ & $6.0(2.3)$ & .003 \\
\hline Transfusion need & $111.5(37)$ & $15.1(6.1)$ & $<.001$ \\
\hline Stroke & $4.2(1.4)$ & $2.5(1.0)$ & .741 \\
\hline ICU LOS, d & $1[1 ; 2]$ & $0[0 ; 1]$ & $<.001$ \\
\hline ICU LOS $>1 \mathrm{~d}$ & $128.4(42)$ & $19(7.8)$ & $<.001$ \\
\hline Postoperative LOS, d & $7[5 ; 9]$ & $4[4 ; 6]$ & $<.001$ \\
\hline In-hospital death & $2.8(0.9)$ & $2.7(1.1)$ & .853 \\
\hline Discharge home & $2.5(0.8)$ & $170.6(69)$ & $<.001$ \\
\hline N & &
\end{tabular}

Numbers in brackets report interquartile range. SoW, Sum of weights; $M R$, mitral regurgitation; $L C O S$, low cardiac output syndrome; $M D$, medium dosage, $\geq$ adrenalin $0.05 \mathrm{\gamma} / \mathrm{kg} / \mathrm{min}$ or association of 2 inotropes; $A K I$, acute kidney injury; $N I M V$, noninvasive mechanical ventilation; $I C U$, intensive care unit; $L O S$, length of stay.

to reintervention/reoperation was 7.9 (3.4-15.6) months. Four patients ( 3 MitraClip and 1 surgical) could be retreated with a new MitraClip. The remaining 6 (3 MitraClip, 3 surgical) required valve replacement.

\section{DISCUSSION}

The main findings of this study were that, in an average daily practice low-to-intermediate risk elderly patient population affected by DMR, compared with surgery, MitraClip was associated with: (1) lower rate of acute complications; (2) improved survival within 1 year but reduced survival beyond 1 year; and (3) increased MR recurrence. Baseline patients' greater-risk profile and MR recurrence predicted reduced survival.

The present study is the first to try to address a weighted comparison between MitraClip and surgery in the aforementioned patient population. Previously, the failure of the HiRiDe Randomized Trial underlined the difficulties to conduct a proper study in a high-risk elderly population affected by MR. The use of ATE weights allowed us to compare outcomes between MitraClip and surgery as all patients could receive either of the 2 , thus simulating a randomized trial, on low-to-intermediate risk all-comers. Indeed, with the expansion of transcatheter technologies, the dilemma we are currently facing in the clinical practice is to understand what is the best treatment option for "gray" elderly patients who typically present a low-to-intermediate risk profile but also a very advanced age (often older than 


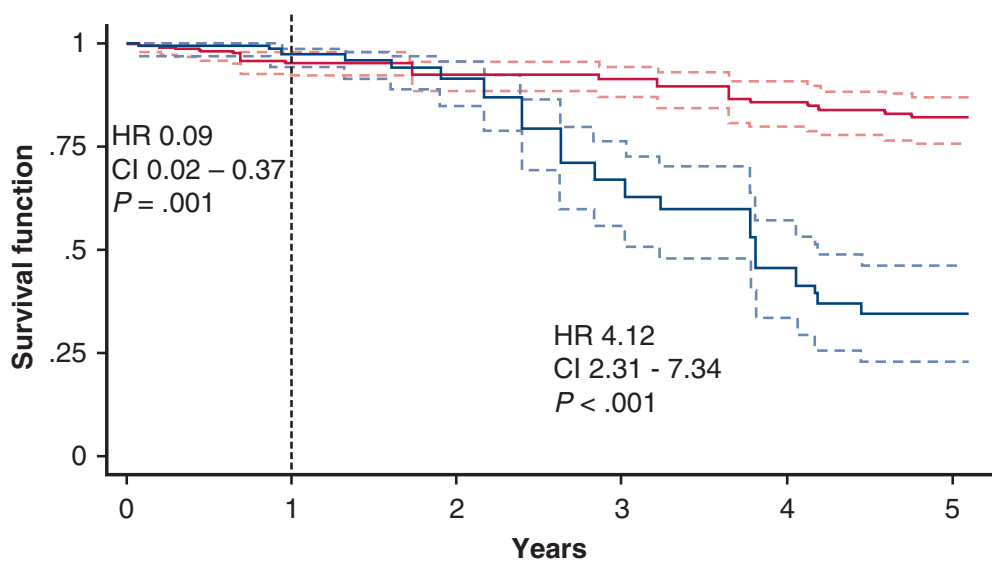

$\begin{array}{rccccc}\text { Number at risk } & & & & \\ \text { Surgery 294.4 } & 242.3 & 177.7 & 147.3 & 121.4 & 100.0 \\ \quad \text { A } \quad \text { Mitraclip 243.2 } & 163.3 & 77.1 & 41.5 & 25.0 & 15.8\end{array}$

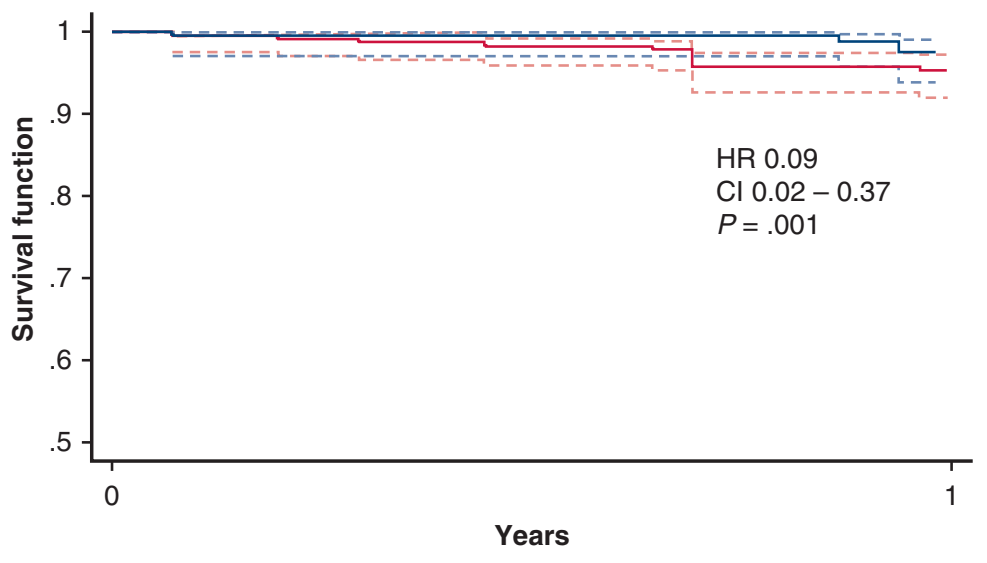

Number at risk

Surgery 294.4
Mitraclip 243.2

242.3

163.3

B

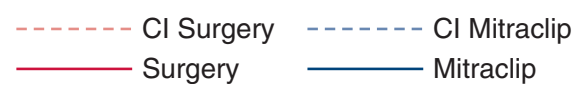

FIGURE 2. Average treatment effect-weighted Kaplan-Meier survival estimates up to 5 years (A) and up to 1 year (B) after the procedure. The HR of death with MitraClip compared with surgery is lower within but greater beyond 1 year. HR, Hazard ratio; $C I$, confidence interval.

80 years). In such scenario, the burden of surgery and the patients' perceived short life expectancy often make the new less-invasive transcatheter devices appear particularly appealing.

TABLE 4. Weighted Cox model for all-cause death

\begin{tabular}{lccc}
\hline & HR & $\boldsymbol{P}$ value & $\mathbf{9 5} \% \mathbf{C I}$ \\
\hline STS-PROM & 1.18 & $<.001$ & $1.12-1.24$ \\
MitraClip $(\mathrm{t}<1 \mathrm{y})$ & 0.09 & .001 & $0.02-0.37$ \\
MitraClip $(\mathrm{t}>1 \mathrm{y})$ & 4.12 & $<.001$ & $2.31-7.34$ \\
MR $\geq 3+$ recurrence & 2.19 & .033 & $1.07-4.48$ \\
\hline
\end{tabular}

$H R$, Hazard ratio; $C I$, confidence interval; STS-PROM, Society of Thoracic Surgeons Predicted Risk Of Mortality; $M R$, mitral regurgitation.
As predicted, MitraClip was confirmed to be safer than surgery in the short term. Indeed, all acute postoperative complications, such as low cardiac output syndrome, acute kidney injury, prolonged ventilation, bleedings, as well as postoperative length of stay were significantly reduced, with the vast majority of patients discharged directly home without need of rehabilitation. Quick return to normal life and home environment with early full recovery represents a critical advantage in the delicate elderly setting.

Moreover, for the first time ever, the hazard of follow-up mortality within 1 year from the procedure was observed to be lower after MitraClip compared with surgery. Although numbers are still relatively small and more data will be needed to confirm this trend, the result is promising and 


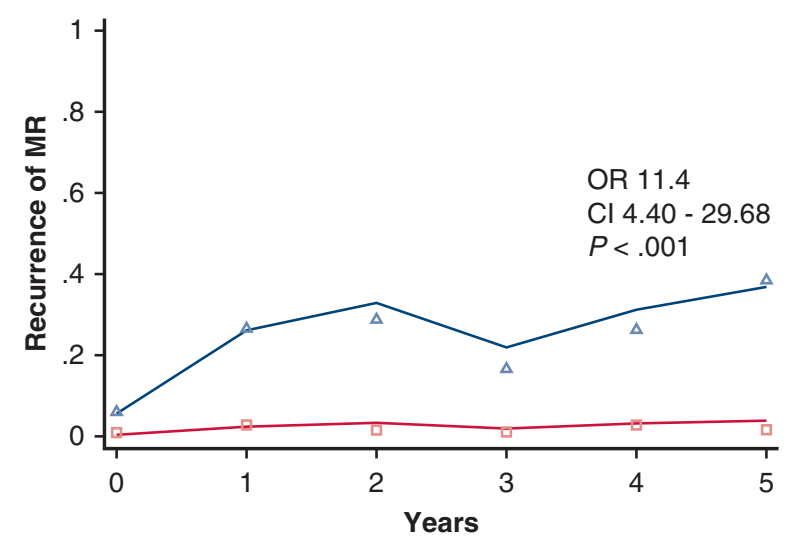

FIGURE 3. Average treatment effect-weighted longitudinal mixed model for evolution of $\mathrm{MR} \geq 3+$ after the procedure. $M R$, Mitral regurgitation; $O R$, odds ratio; $C I$, confidence interval.

worth to be noted. It is also perfectly reasonable, given MitraClip's reduced invasiveness compared with surgery, resembling the experience with transcatheter versus surgical aortic valve replacement. ${ }^{21}$ Indeed, mitral surgery carries a burden that continues to express over several weeks or even months after the operation. ${ }^{3}$

Beyond 1 year after the procedure, however, survival after MitraClip fell unfavorably compared with surgery. In this regard, it must be pointed out that possible uncaptured confounding factors (such as frailty) and imperfect statistical balance between the 2 groups due to the limited numbers may partially justify such difference. Certainly, a sicker profile (as described by the STS-PROM) and the recurrence of MR were associated with an increased mortality rate. MR recurrence being frequent after MitraClip and being associated with bad outcomes is no surprise, ${ }^{11,22}$ but the confirmation of these associations in this specific elderly population warrants an improvement in the efficacy of transcatheter mitral repair, especially in the perspective of expanding indications to lower-risk operable patients.

Good sustained results are actually achievable after MitraClip (Video 1), as suggested by the fact that the majority of patients undergoing MitraClip in our series were indeed still free from MR recurrence after 5 years. While our analysis for predictors of MR recurrence after MitraClip is limited and should only be considered hypothesis generating, it provides interesting insights.

TABLE 5. Longitudinal analysis for predictors of MR recurrence within 3 years in MitraClip patients with initial residual $M R \leq 2+$

\begin{tabular}{lccc}
\hline & OR & $\boldsymbol{P}$ value & $\mathbf{9 5} \% \mathbf{C I}$ \\
\hline Valve calcifications & 1.18 & .84 & $0.29-6.12$ \\
Isolated P2 prolapse & 0.43 & .23 & $0.1-1.71$ \\
Center (Milan) & 0.09 & .004 & $0.02-0.48$ \\
Residual 2+ MR & 12.0 & $<.001$ & $3.22-44.60$ \\
\hline
\end{tabular}

$O R$, Odds ratio; $C I$, confidence interval; $M R$, mitral regurgitation.

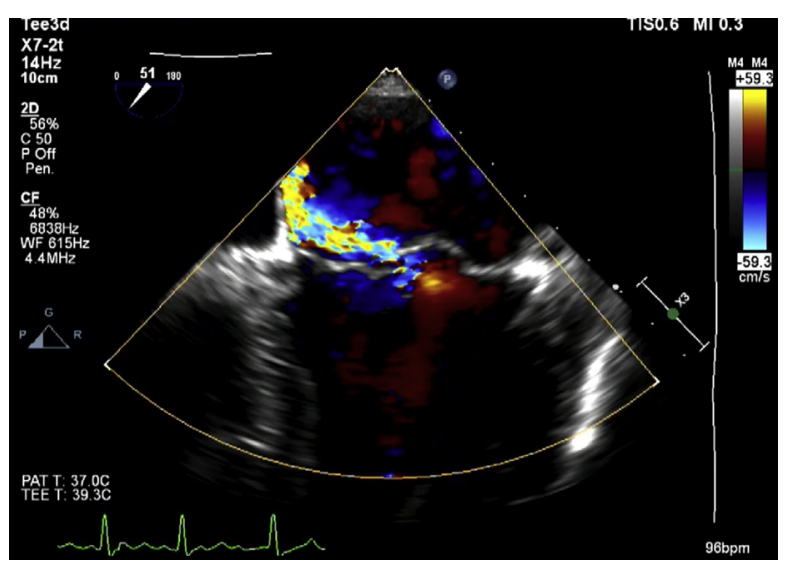

VIDEO 1. A typical case of elderly patient treated with the percutaneous MitraClip procedure. Video available at: https://www.jtcvs.org/article/ S0022-5223(19)30232-6/fulltext.

Most important, worse follow-up MR was observed when $2+$ residual MR was present immediately at the end of the procedure. This has been already previously described, both after surgical mitral repair ${ }^{23}$ and MitraClip. ${ }^{24,25}$ Residual $2+$ MR is common after MitraClip and is still often considered "acceptable" in the elderly people, who have a perceived reduced functional capacity and life expectancy. That concept may be accepted in very old, very sick cases, and we do recognize that $\leq 1+$ residual MR cannot be achieved in each and every single case. Nevertheless, increasing evidence suggests that in the lowto-intermediate risk people, despite advance age, every effort should be made to minimize residual MR, otherwise MR will increase over time and impair survival in the long run.

Some influence of the institutions on follow-up MR was also observed, underlining the importance of experienced operators and teams in such complex procedures, especially in the very early phase of adoption.

It should also be underlined that MitraClip's edge-toedge should not be considered a "procedure" per se but rather just one "tool" to be used within a mitral repair procedure, the same way a 4-0 PROLENE suture is used in surgery. Like in surgery, other tools addressing other mitral targets will be needed to achieve full optimization of transcatheter mitral repair. Most important, it is well documented across the surgical literature that the absence of ring implantation is one of the strongest predictors of MR recurrence after mitral repair, even with the edge-to-edge technique. ${ }^{26}$ Transcatheter mitral rings have recently started to provide promising results, ${ }^{27}$ and we are looking forward to combining different transcatheter technologies in the future, targeting both the mitral leaflets and the annulus, as we do in surgery, to provide a tailored treatment and improve the efficacy of transcatheter mitral repair.

In the complex scenario that is the elderly patient, the choice of the best treatment should be individualized per 
each single person, being tailored through a Heart Team approach to the patient anatomy, risk, need, and desire.

\section{Study Limitations}

Several limitations of this study must be acknowledged. First, its retrospective nature may have led to biases like the impossible collection of variables such as quality of life, frailty, or other potential confounding factors. Frailty in particular is an important missing variable, the assessment of which remains not standardized and uncommon in the clinical daily practice. Also, precise scallop-byscallop anatomy pairing was not considered into the propensity score model because of the too-small number of patients. Second, because of the small numbers of patients and events, the best IPTW model that could be achieved allowed sufficient but not perfect balance between groups, with some ASMD between 0.1 and 0.2 ; the overall statistical power of the study was also limited. Third, because the present series includes MitraClip procedures performed since the beginning of centers' experiences, a learning curve effect should be taken into account. Fourth, echocardiographic evaluation was performed on site, without a core-lab re-adjudication. The evaluation of MR in the subverted double-orifice valve anatomy remains challenging and may have led to biased estimation of real MR. Greater rigor in the echocardiographic follow-up, technique, and analysis in the MitraClip group could have biased the long-term MR results. For the aforementioned reasons, our findings should only be considered hypothesisgenerating and they should be confirmed by larger data.

\section{CONCLUSIONS}

In the average low-to-intermediate risk elderly affected by DMR, MitraClip was associated with lower acute postoperative complications and increased survival within 1 year compared with surgery but also with greater MR recurrence and reduced survival beyond 1 year. Longterm survival was impaired by patients' greater risk profile and MR recurrence. Although early results are promising, in the setting of operable patients with life expectancy beyond 1 year, the quality bar for transcatheter mitral repair needs to be raised.

\section{Conflicts of Interest}

Dr Denti is a consultant for Abbott Vascular, Valtech, 4Tech Cardio, and InnovHeart. Dr Taramasso is a consultant for Abbott Vascular and 4Tech Cardio. Dr Maisano is a consultant for Abbott Vascular, St Jude Medical, Medtronic, Valtech Cardio, Bioventrix, Direct Flow, Edwards Lifescience, and Xeltis and he is co-founder of 4Tech Cardio, AFfix, and TSP Medical. All other authors have nothing to disclose with regard to commercial support.

\section{References}

1. Mehta RH, Eagle KA, Coombs LP, Peterson ED, Edwards FH, Pagani FD, et al Influence of age on outcomes in patients undergoing mitral valve replacement. Ann Thorac Surg. 2002;74:1459-67.

2. Detaint D, Sundt TM, Nkomo VT, Scott CG, Tajik AJ, Schaff HV, et al. Surgical correction of mitral regurgitation in the elderly: outcomes and recent improvements. Circulation. 2006;114:265-72.

3. Chikwe J, Goldstone AB, Passage J, Anyanwu AC, Seeburger J, Castillo JG, et al. A propensity score-adjusted retrospective comparison of early and mid-term results of mitral valve repair versus replacement in octogenarians. Eur Heart $J$ 2011;32:618-26.

4. Badhwar V, Peterson ED, Jacobs JP, He X, Brennan JM, O’Brien SM, et al. Longitudinal outcome of isolated mitral repair in older patients: results from 14,604 procedures performed from 1991 to 2007. Ann Thorac Surg. 2012;94:1870-7; discussion 1877-9.

5. Mirabel M, Iung B, Baron G, Messika-Zeitoun D, Detaint D, Vanoverschelde JL, et al. What are the characteristics of patients with severe, symptomatic, mitral regurgitation who are denied surgery? Eur Heart J. 2007;28:1358-65.

6. Maisano F, Franzen O, Baldus S, Schafer U, Hausleiter J, Butter C, et al. Percutaneous mitral valve interventions in the real world: early and 1-year results from the ACCESS-EU, a prospective, multicenter, nonrandomized post-approval study of the MitraClip therapy in Europe. J Am Coll Cardiol. 2013;62:1052-61.

7. Buzzatti N, Maisano F, Latib A, Taramasso M, Denti P, La Canna G, et al. Comparison of outcomes of percutaneous MitraClip versus surgical repair or replacement for degenerative mitral regurgitation in octogenarians. Am J Cardiol. 2015; 115:487-92.

8. Lim DS, Reynolds MR, Feldman T, Kar S, Herrmann HC, Wang A, et al. Improved functional status and quality of life in prohibitive surgical risk patients with degenerative mitral regurgitation after transcatheter mitral valve repair. $J$ Am Coll Cardiol. 2014;64:182-92.

9. Baumgartner H, Falk V, Bax JJ, De Bonis M, Hamm C, Holm PJ, et al. 2017 ESC/ EACTS guidelines for the management of valvular heart disease. Eur Heart J. 2017:38:2739-91.

10. Nishimura RA, Otto CM, Bonow RO, Carabello BA, Erwin JP III, Fleisher LA et al. 2017 AHA/ACC focused update of the 2014 AHA/ACC guideline for the management of patients with valvular heart disease: a report of the American College of Cardiology/American Heart Association task force on clinical practice guidelines. J Am Coll Cardiol. 2017;70:252-89.

11. Feldman T, Kar S, Elmariah S, Smart SC, Trento A, Siegel RJ, et al. Randomized comparison of percutaneous repair and surgery for mitral regurgitation: 5-year results of EVEREST II. J Am Coll Cardiol. 2015;66:2844-54.

12. Mauri L, Garg P, Massaro JM, Foster E, Glower D, Mehoudar P, et al. The EVER EST II Trial: eesign and rationale for a randomized study of the evalve MitraClip system compared with mitral valve surgery for mitral regurgitation. Am Heart J. 2010;160:23-9.

13. Lancellotti P, Moura L, Pierard LA, Agricola E, Popescu BA, Tribouilloy C, et al European Association of Echocardiography recommendations for the assessment of valvular regurgitation. Part 2: mitral and tricuspid regurgitation (native valve disease). Eur J Echocardiogr. 2010;11:307-32.

14. Stone GW, Adams DH, Abraham WT, Kappetein AP, Genereux P, Vranckx P, et al. Clinical trial design principles and endpoint definitions for transcatheter mitral valve repair and replacement: part 2: endpoint definitions: a consensus document from the Mitral Valve Academic Research Consortium. J Am Coll Cardiol. 2015;66:308-21.

15. Zoghbi WA, Enriquez-Sarano M, Foster E, Grayburn PA, Kraft CD, Levine RA, et al. Recommendations for evaluation of the severity of native valvular regurgitation with two-dimensional and Doppler echocardiography. J Am Soc Echocardiogr. 2003; 16:777-802.

16. Austin PC. An introduction to propensity score methods for reducing the effects of confounding in observational studies. Multivariate Behav Res. 2011;46: 399-424.

17. Lee BK, Lessler J, Stuart EA. Weight trimming and propensity score weighting PLoS One. 2011;6:e18174.

18. Austin PC, Stuart EA. Moving towards best practice when using inverse probability of treatment weighting (IPTW) using the propensity score to estimate causal treatment effects in observational studies. Stat Med. 2015;34:3661-79.

19. Harder VS, Stuart EA, Anthony JC. Propensity score techniques and the assessment of measured covariate balance to test causal associations in psychological research. Psychol Methods. 2010;15:234-49.

20. De Bonis M, Lapenna E, Del Forno B, Di Sanzo S, Giacomini A, Schiavi D, et al Minimally invasive or conventional edge-to-edge repair for severe mitral 
regurgitation due to bileaflet prolapse in Barlow's disease: does the surgical approach have an impact on the long-term results? Eur J Cardiothorac Surg. 2017;52:131-6.

21. Reardon MJ, Kleiman NS, Adams DH, Yakubov SJ, Coselli JS, Deeb GM, et al. Outcomes in the randomized corevalve US Pivotal high risk trial in patients with a Society of Thoracic Surgeons risk score of 7\% or less. JAMA Cardiol. 2016;1:945-9.

22. Suri RM, Clavel MA, Schaff HV, Michelena HI, Huebner M, Nishimura RA, et al Effect of recurrent mitral regurgitation following degenerative mitral valve repair: long-term analysis of competing outcomes. J Am Coll Cardiol. 2016;67:488-98.

23. De Bonis M, Lapenna E, Lorusso R, Buzzati N, Gelsomino S, Taramasso M, et al Very long-term results (up to 17 years) with the double-orifice mitral valve repair combined with ring annuloplasty for degenerative mitral regurgitation. J Thorac Cardiovasc Surg. 2012;144:1019-26.

24. Buzzatti N, De Bonis M, Denti P, Barili F, Schiavi D, Di Giannuario G, et al What is a "good" result after transcatheter mitral repair? Impact of $2+$ residual mitral regurgitation. J Thorac Cardiovasc Surg. 2016;151:88-96.
25. Toggweiler S, Zuber M, Surder D, Biaggi P, Gstrein C, Moccetti T, et al. Twoyear outcomes after percutaneous mitral valve repair with the MitraClip system: durability of the procedure and predictors of outcome. Open Heart. 2014;1: e000056.

26. De Bonis M, Lapenna E, Maisano F, Barili F, La Canna G, Buzzatti N, et al. Long-term results $(</=18$ years $)$ of the edge-to-edge mitral valve repair without annuloplasty in degenerative mitral regurgitation: implications for the percutaneous approach. Circulation. 2014;130:S19-24.

27. Maisano F, Taramasso M, Nickenig G, Hammerstingl C, Vahanian A, MessikaZeitoun D, et al. Cardioband, a transcatheter surgical-like direct mitral valve annuloplasty system: early results of the feasibility trial. Eur Heart J. 2016;37: $817-25$.

Key Words: mitral regurgitation, degenerative, prolapse, Mitraclip, mitral repair, transcatheter

Readers who found these articles interesting may also like to read the following papers found in recent and future issues of our sister publications, Seminars in Thoracic and Cardiovascular Surgery and Operative Techniques in Thoracic and Cardiovascular Surgery!

\section{Adult: Mitral Valve}

ORIGINAL SUBMISSION: The Clinical Significance of Cerebral Microbleeds in Infective Endocarditis Patients. Ryosuke Murai. Semin Thoracic Surg 2019: 51-58.

Commentary: The truth perturbs in the seemingly negligible; brain magnetic resonance imaging and endocarditis. Ari A. Mennander Semin Thoracic Surg 2019: 59-60.

ORIGINAL MANUSCRIPT: Mathematical Blueprint of a Mitral Valve. Pramod N. Bonde. Semin Thoracic Surg 2019: In press. Commentary: Simulating the mitral apparatus. Antonio Miceli. Semin Thoracic Surg 2019: In press.

SURGICAL TECHNIQUE: Five Maneuvers to Facilitate Faster Robotic Mitral Valve Repair. Marc Gillinov. Semin Thoracic Surg 2019: 48-50.

CASE REPORT: Minimally Invasive SAPIEN in Mitral Annular Calcification Following Transcatheter Aortic Valve Replacement: Feasibility and Lessons Learned. Tom C. Nguyen. Semin Thoracic Surg 2018: 290-292. 


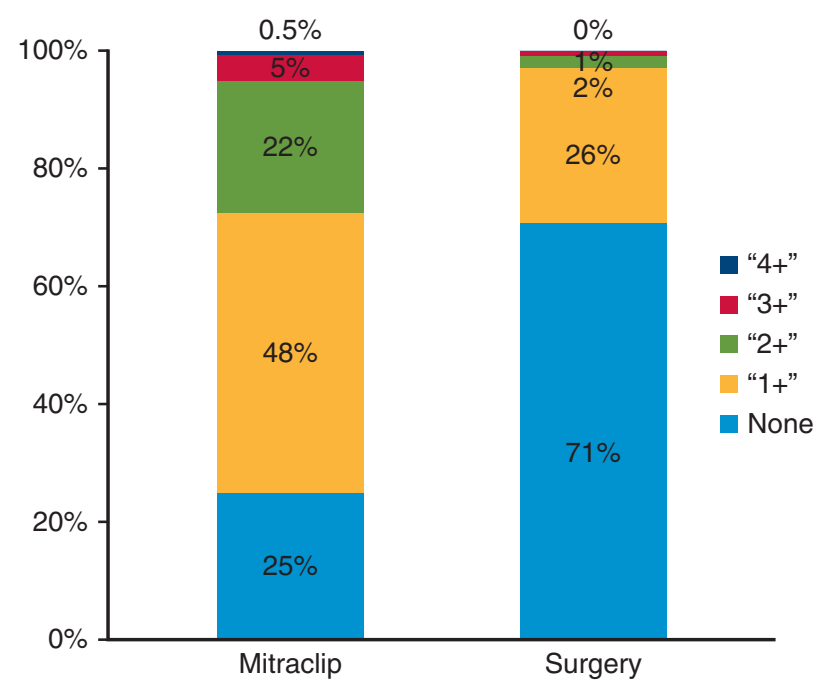

FIGURE E1. Weighted residual mitral regurgitation at the end of the procedure.

TABLE E1. Raw un-weighted number of available echocardiograms during follow-up

\begin{tabular}{lcc}
\hline Time, $\mathbf{y}$ & MitraClip & Surgery \\
\hline 0 & 100 & 206 \\
1 & 94 & 178 \\
\hline 2 & 59 & 131 \\
3 & 30 & 93 \\
4 & 19 & 72 \\
5 & 14 & 62 \\
\hline
\end{tabular}

